\title{
SOIL RADIOACTIVITY LEVELS, RADIOLOGICAL MAPS AND RISK ASSESSMENT FOR THE STATE OF KUWAIT
}

\author{
N. Alazemi ${ }^{\mathrm{a}, \mathrm{b}}$, A.D. Bajoga ${ }^{* a, c, d}$, D. A. Bradley ${ }^{\mathrm{a}}$, , P. H. Regan ${ }^{\mathrm{a}, \mathrm{d}}$, H. Shams ${ }^{\mathrm{a}, \mathrm{b}}$ \\ ${ }^{\mathrm{a}}$ Department of Physics, University of Surrey, Guildford, GU2 7XH, UK \\ ${ }^{\mathrm{b}}$ Environmental Radiation Protection Laboratory, Qadesiyah, PO Box 16087, Kuwait. \\ ${ }^{\mathrm{c}}$ Department of Physics, Gombe State University, Gombe, Nigeria \\ ${ }^{\mathrm{d}}$ National Physical Laboratory, Teddington, Middlesex, TW11 0LW, UK
}

\begin{abstract}
An evaluation of the radioactivity levels associated with naturally occurring radioactive materials has been undertaken as part of a systematic study to provide a surface radiological map of the State of Kuwait. Soil samples from across Kuwait were collected, measured and analysed in the current work. These evaluations provided soil activity concentration levels for primordial radionuclides, specifically members of the ${ }^{238} \mathrm{U}$ and ${ }^{232} \mathrm{Th}$ decay chains and ${ }^{40} \mathrm{~K}$ which. The ${ }^{238} \mathrm{U}$ and ${ }^{232} \mathrm{Th}$ chain radionuclides and ${ }^{40} \mathrm{~K}$ activity concentration values ranged between $5.9 \leftrightarrow 32.3,3.5-\leftrightarrow 27.3$, and $74 \leftrightarrow 698 \mathrm{~Bq} / \mathrm{kg}$ respectively. The evaluated average specific activity concentrations of ${ }^{238} \mathrm{U},{ }^{232} \mathrm{Th}$ and ${ }^{40} \mathrm{~K}$ across all of the soil samples have mean values of 18,15 and $385 \mathrm{~Bq} / \mathrm{kg}$ respectively, all falling below the worldwide mean values of 35,40 and $400 \mathrm{~Bq} / \mathrm{kg}$ respectively. The radiological risk factors are associated with a mean of $33.16 \pm 2.46 \mathrm{nG} / \mathrm{hr}$ and $68.5 \pm 5.09 \mathrm{~Bq} / \mathrm{kg}$ for the external dose rate and Radium equivalent respectively. The measured annual dose rates for all samples gives rise to a mean value of $40.8 \pm 3.0 \mu \mathrm{Sv} / \mathrm{y}$ while the internal and internal hazard indices have been found to be $0.23 \pm 0.02$ and $0.19 \pm 0.01$ respectively.
\end{abstract}

Keywords: Baseline studies, NORM, natural radioactivity, activity concentration, Radium equivalent, Dose rates, Hazard indices.

\section{*Corresponding author:}

E-mail address:- a.bajoga@ surrey.ac.uk

Tel.: +44 (0) 79093 26405; Fax: +44 (0) 1483686781

\section{Introduction}

Anthropogenic radioactivity comes in different forms and arises from a range of applications, including nuclear medicine, energy production, and industrial and agricultural applications. Anthropogenic radionuclides are released into the environment due to nuclear weapon tests, effluent discharges from nuclear facilities, and reactor accidents. Man-made radioisotopes discharged from such sources can be retained in environmental materials including 
soil. However, even with this artificial utilization of radioactivity, up to $85 \%$ of the typical human annual exposure dose received by the world population arises from naturally occurring radioactive material, NORM (WNA, 2011). Industrial processes involving NORM can also carry an associated radiological risk and therefore identifying, quantifying, evaluating and managing any such risks are important (Baeza et al., 2011; G. Xhixha et al., 2015).

The State of Kuwait lies between longitude $46-48^{\circ}$ east and latitude $28-31^{\circ}$ north, is located in the Middle East at the tip of the Persian Gulf, bordered by Iraq and Saudi Arabia (Fig. 1) and covering a land mass area of $17,820 \mathrm{~km}^{2}$. According to a recent estimate, it has a population of about 4 million (Government of Kuwait, 2014). According to Saad and Al-Azmi (2002) and Jallad (2013), the geological topography of Kuwait is relatively uniform, with smooth sand-sheets and having relatively consistent concentrations of radionuclides of natural origin.

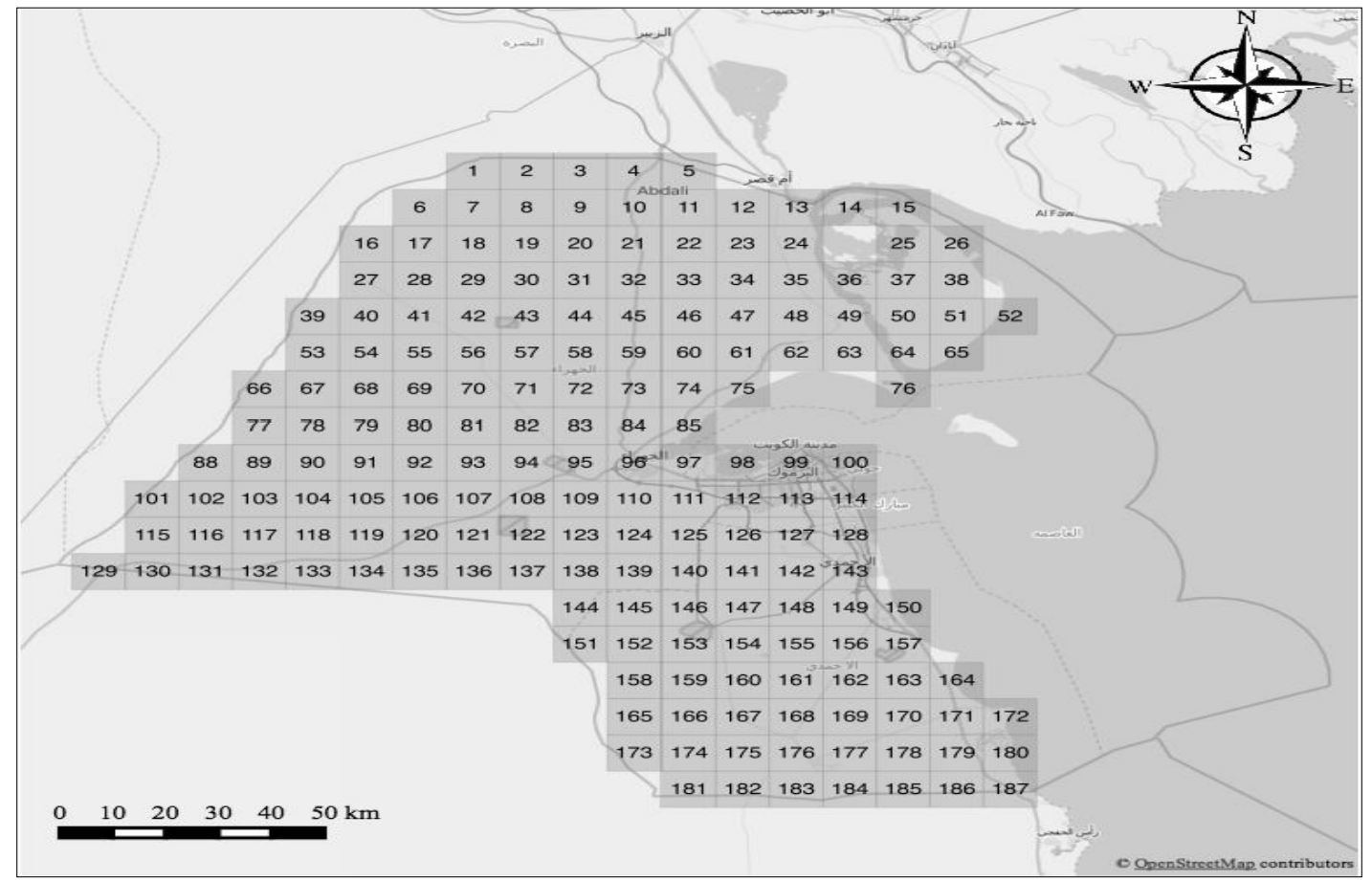

Fig.1. The map of Kuwait, showing the sampling collection sites used in the current work.

The aim of this study is to produce a comprehensive radiation map of the State of Kuwait that is intended to serve as a reference for future radiological evaluations of the region. This is achieved 
by determining the levels of radioactive concentrations from the ${ }^{238} \mathrm{U}\left({ }^{226} \mathrm{Ra}\right)$ and ${ }^{232} \mathrm{Th}\left({ }^{228} \mathrm{Ac}\right)$ decay series, along with ${ }^{40} \mathrm{~K}$, using high resolution $\gamma$-ray spectrometry with a hyper-pure germanium detector retained in a low background configuration. Values from the measured activity concentration can be used to characterise the radiological risk associated with these sample locations. Results obtained from the analysis of approximately 180 samples from across Kuwait are presented in this paper. There is a growing interest across the world to establish national baseline terrestrial radiation levels (Al-Jundi et al., 2003; Al-Sulaiti et al., 2009; Saad and Al-Azmi., 2002; Al-Hamarneh and Awadallah, 2009; Dawood, 2011), intended to be of utility in evaluation and provision of future baseline values associated with other locations from the particular regions.

\section{Material and methods}

\subsection{Sample collection and preparation}

The approximately 180 separate soil and sand samples that were collected from a wide variety of locations in Kuwait were shipped to the University of Surrey for further analysis, based on techniques that have been outlined in Santawamaitre et al. (2014). The samples were taken to the Environmental Radioactivity Laboratory at the University where they were sieved using a 2 $\mathrm{mm}$ sieve to remove any unwanted impurities such as twigs, vegetation and glass. After sieving, the samples were dried in a drying oven to remove any moisture present in the soil. Additional sieving using a $500 \mu \mathrm{m}$ sieve was then performed to produce uniform and homogeneous samples. The sieved soil was put into Marinelli beakers and sealed with tape to be air tight, to prevent escape of gaseous decay progeny (eg. $\left.{ }^{222} \mathrm{Rn}\right)$. The beakers were then stored for a minimum of 1 month to achieve secular equilibrium between ${ }^{226} \mathrm{Ra}$ and ${ }^{222} \mathrm{Rn}$.

\subsection{Instrumentation and calibration}

Two independent HPGe detectors were used for the gamma-ray spectrometric measurement of the samples. These systems both had measured FWHM energy resolutions of $0.8 \mathrm{keV}$ and 2.0 $\mathrm{keV}$ for the $122 \mathrm{keV}\left({ }^{57} \mathrm{Co}\right)$ and $1332 \mathrm{keV}\left({ }^{60} \mathrm{Co}\right)$ lines respectively.. Prior to beginning the measurements, both the detectors underwent full energy and full-energy peak total efficiency calibration procedures using four standard reference sources, viz, ${ }^{226} \mathrm{Ra},{ }^{232} \mathrm{Th}{ }^{152} \mathrm{Eu}$, and an NG3 mixed source containing ${ }^{57} \mathrm{Co},{ }^{60} \mathrm{Co},{ }^{85} \mathrm{Sr},{ }^{88} \mathrm{Y},{ }^{109} \mathrm{Cd},{ }^{137} \mathrm{Cs},{ }^{139} \mathrm{Ce},{ }^{203} \mathrm{Hg}$ and ${ }^{241} \mathrm{Am}$. These gave accurate representations of the efficiency of the counting systems for soil samples. The standard 
sources were measured for 48 hours and results were used for determination of the efficiency curve. Each of the sources was contained in a $550 \mathrm{ml}$ Marinelli beaker of the same geometry as those used in the sample measurements.

\subsection{Activity concentration determination}

Each prepared soil sample was measured for 48 hours using a hyper-pure germanium (HPGe) detector. The net counts under the full-energy peak areas, the counting time, the absolute fullenergy peak efficiency for the energy of interest and the gamma-ray emission probability corresponding to the peak energy were used to determine the activity concentration of a particular radionuclide in the measured samples. Prior to that a background radiation level of the HPGe system was obtained by counting deionized water for the same duration (48 hours) in a $550 \mathrm{ml}$ Marinelli beaker which again had the same geometry as that in counting of the sample. The background spectrum was later subtracted from each sample spectra before activity concentration determination. The quoted specific activity concentration values (in $\mathrm{Bq} / \mathrm{kg}$ ) assume secular equilibrium for the different isotopic activities in the decay chains and is defined as the activity per unit mass of the sample (Dovlete and Povinec, 2004), expressed as:

$$
A=\frac{C_{n}}{\varepsilon_{f} P_{\gamma} t_{s} m}
$$

where $A$ is the activity concentration of a particular nuclide in units of Bq. $\mathrm{kg}^{-1}, C_{n}$ the net count (background subtracted) of the corresponding full energypeak, $\varepsilon_{\gamma}$ the absolute full-energy peak detection efficiency, $P_{\gamma}$ the emission probability per decay corresponding to the specific gammaray energy, $t$ the counting time in second and $m$ the mass of soil sample in $\mathrm{kg}$.

The activity determined for ${ }^{226} \mathrm{Ra}$ using the $186.2 \mathrm{keV}$ transition was adjusted to correct for the contribution from the overlapping gamma-ray transition associated with the alpha decay of ${ }^{235} \mathrm{U}$ to ${ }^{231} \mathrm{Th}$ at $185.7 \mathrm{keV}$ (Gilmore, 2008; Newman et al., 2008). Strongly populated gamma-ray transitions identified in the soil spectra were used to calculate the activity concentration along with the uncertainty associated with each specific radioisotope. These measurements take into account the standard deviation uncertainties associated with statistical counting uncertainties in the peak area, gamma-ray emission probability and full-energy peak detection efficiency. These 
were then combined for each specific decay chain to give a weighted mean and uncertainty on the weighted mean for the ${ }^{238} \mathrm{U}\left({ }^{226} \mathrm{Ra}\right)$ and ${ }^{232} \mathrm{Th}$ decay chains. The weighted mean analysis is employed in order to achieve the best estimate of the activity concentration. This is done by use of independent measurements of multiple, discrete gamma-ray lines from the same decay chains thereby ensuring a significant reduction in the statistical uncertainty of the derived activity concentrations compared to use of a single transition. The horizontal lines in Figure 2 correspond to the weighted mean of the individual data points. An example of weighted mean from sample no. 21 is shown in Fig. 2, with the horizontal line giving the weighted mean activity concentration of that decay chain. The +ve and -ve signs represent the $1 \sigma$ uncertainty limits associated with the weighted mean values. The activity concentrations of the primordial radionuclide ${ }^{40} \mathrm{~K}$ was derived directly from the measured intensity of the single $1460.8 \mathrm{keV}$ gamma-ray transition.

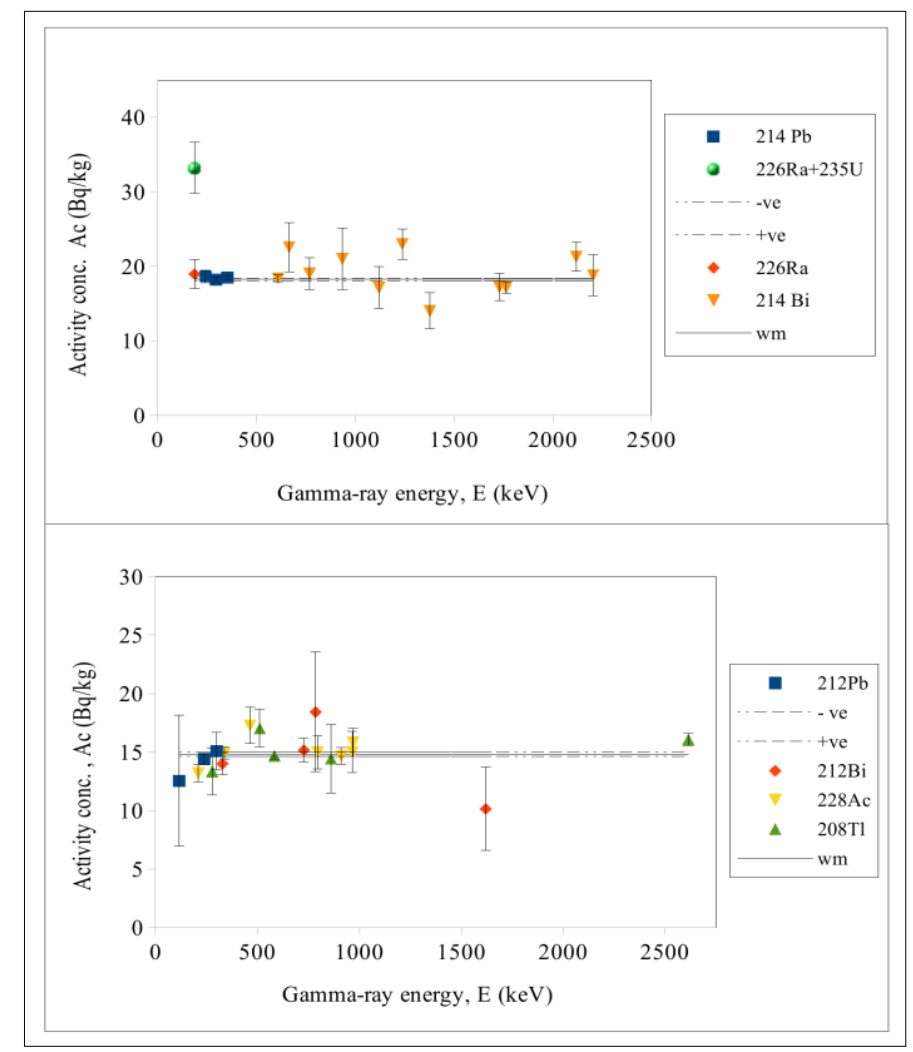

Fig.2. Weighted mean evaluation for Sample 21 showing data from individual gamma-ray transitions following decays of ${ }^{214} \mathrm{Bi},{ }^{214} \mathrm{~Pb}$ and ${ }^{226} \mathrm{Ra}$ from the ${ }^{238} \mathrm{U}$ decay chain and ${ }^{228} \mathrm{Ac}$ and ${ }^{208} \mathrm{TI}$ from the ${ }^{232} \mathrm{Th}$ decay chain. 


\subsection{Radiological risk assessment}

The dose rates (D) for the measured samples were determined from the specific activity concentration, in addition to the associated radiological risks from the absorbed dose at $1 \mathrm{~m}$ above the ground surface, viz, the radium equivalent activity $\left(\mathrm{Ra}_{\mathrm{eq}}\right)$ which is used to assess hazards associated with materials containing ${ }^{226} \mathrm{Ra},{ }^{232} \mathrm{Th}$ and ${ }^{40} \mathrm{~K}$ nuclides; internal hazards index $\left(H_{\text {int }}\right)$, external hazard index $\left(H_{e x t}\right)$ and finally the effective dose rates (AEDE) were calculated using the following references (Berekta and Mathews, 1985; UNSCEAR, 1988; Kumar et.al., 2003; Dragovic et. al., 2006). $H_{\text {int }}$ gives a measure of internal exposure due to radon $\left({ }^{222} \mathrm{Rn}\right)$ and the index must be less than unity to be within the safety threshold, whereas the $H_{\text {ext }}$ index evaluates external radiation exposure from radium containing materials. A value of $H_{e x t}=1$ represents the maximum permissible value equivalent to a radium equivalent activity of $370 \mathrm{~Bq} / \mathrm{kg}$.

$$
\begin{aligned}
& \mathrm{Ra}_{\mathrm{eq}}=\mathrm{A}_{\mathrm{U}}+\left(\mathrm{A}_{\mathrm{Th}} \times 1.43\right)+\left(\mathrm{A}_{\mathrm{K}} \times 0.077\right) \\
& \mathrm{D}=\left(0.462 \times \mathrm{A}_{\mathrm{U}}\right)+\left(0.604 \times \mathrm{A}_{\mathrm{Th}}\right)+\left(0.0417 \times \mathrm{A}_{\mathrm{K}}\right) \\
& \mathrm{AEDE}=\mathrm{D} \times 1.23 \times 10^{-3} \mathrm{mSv} / \mathrm{y} \\
& \mathrm{H}_{\mathrm{int}}=\left(\frac{A_{U}}{185}+\frac{A_{T h}}{259}+\frac{A_{K}}{4810}\right) \leq 1 \\
& \mathrm{H}_{\mathrm{ext}}=\left(\frac{A_{U}}{370}+\frac{A_{T h}}{259}+\frac{A_{K}}{4810}\right) \leq 1
\end{aligned}
$$

The units for $\mathrm{Ra}_{\mathrm{eq}}, \mathrm{D}$ and $\mathrm{AEDE}$ are given in $\mathrm{Bq} / \mathrm{kg}, \mathrm{nG} / \mathrm{hr}$, and $\mathrm{mSv} / \mathrm{year}$ respectively. The symbols $A_{U}, A_{T h}$, and $A_{K}$ represent the specific activities in $(B q / k g)$ for the ${ }^{238} U$ chain, the ${ }^{232} \mathrm{Th}$ chain and ${ }^{40} \mathrm{~K}$ respectively. 


\section{Results and discussion}

\subsection{Sample spectra}

A representative gamma-ray spectrum from the current measurements, associated with decays from the radionuclides detected from sample No. 4 is shown in Fig. 3. Most of the identified radionuclides observed in the spectrum belong to the $4 n+2$ and $4 n$ decay chain members, specifically from decay of ${ }^{226} \mathrm{Ra},{ }^{214} \mathrm{~Pb}$ and ${ }^{214} \mathrm{Bi}$ from the ${ }^{238} \mathrm{U}$ series; and ${ }^{228} \mathrm{Ac},{ }^{212} \mathrm{~Pb}$, ${ }^{212} \mathrm{Bi}$ and ${ }^{208} \mathrm{Tl}$ from the ${ }^{232} \mathrm{Th}$ decay series respectively. In addition to these, the gamma-ray energy peak from ${ }^{40} \mathrm{~K}$ at $1460.8 \mathrm{keV}$ was also detected, along with the anthropogenic radionuclide ${ }^{137} \mathrm{Cs}$ at $661.6 \mathrm{keV}$, which is a fission product associated from fallout from nuclear weapon tests and nuclear accidents.

\subsection{Soil radioactivity concentration}

The activity concentration for each of the (180) separately measured soil samples is shown in Fig. 4. Results are for the ${ }^{238} \mathrm{U},{ }^{232} \mathrm{Th}$ primordial decay chains, in addition to the singly decaying ${ }^{40} \mathrm{~K}$. It can be observed that there is some level of uniformity across the values. This is consistent with the geology of Kuwait geology, being relatively uniform with smooth sand-sheets, which in turn would lead to the expectation of rather consistent concentrations of radionuclides of natural origin (Saad and Al-Azmi, 2002; Jallad, 2013). However, a small number of exceptions can be observed, specifically in two samples from the southern-western part of the country. This may be due to depletion of these nuclides in these samples, arising from leaching and subsequent transport of these nuclides from these location. The values obtained due to ${ }^{238} \mathrm{U},{ }^{232} \mathrm{Th}$, and ${ }^{40} \mathrm{~K}$ for all the samples range from $5.9 \leftrightarrow 32.3,3.5 \leftrightarrow 27.3$ and $74 \leftrightarrow 698 \mathrm{~Bq} / \mathrm{kg}$ respectively, with respective mean activities of $17.3,15.1$ and $385 \mathrm{~Bq} / \mathrm{kg}$. 


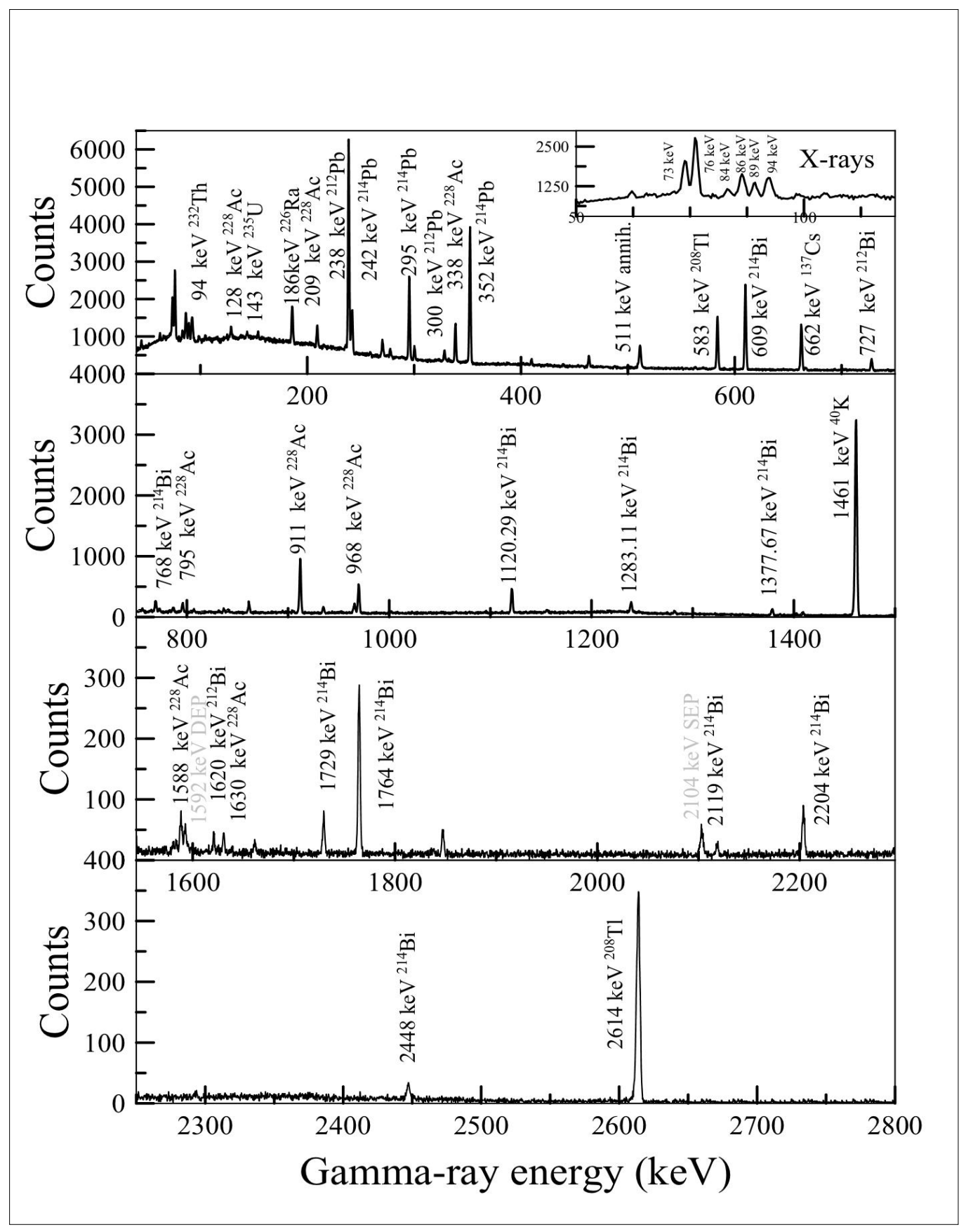

Fig.3. Background-subtracted gamma-ray spectrum associated with decays from ${ }^{238} \mathrm{U}$ and ${ }^{232} \mathrm{Th}$ radionuclides as detected from sample 004. 


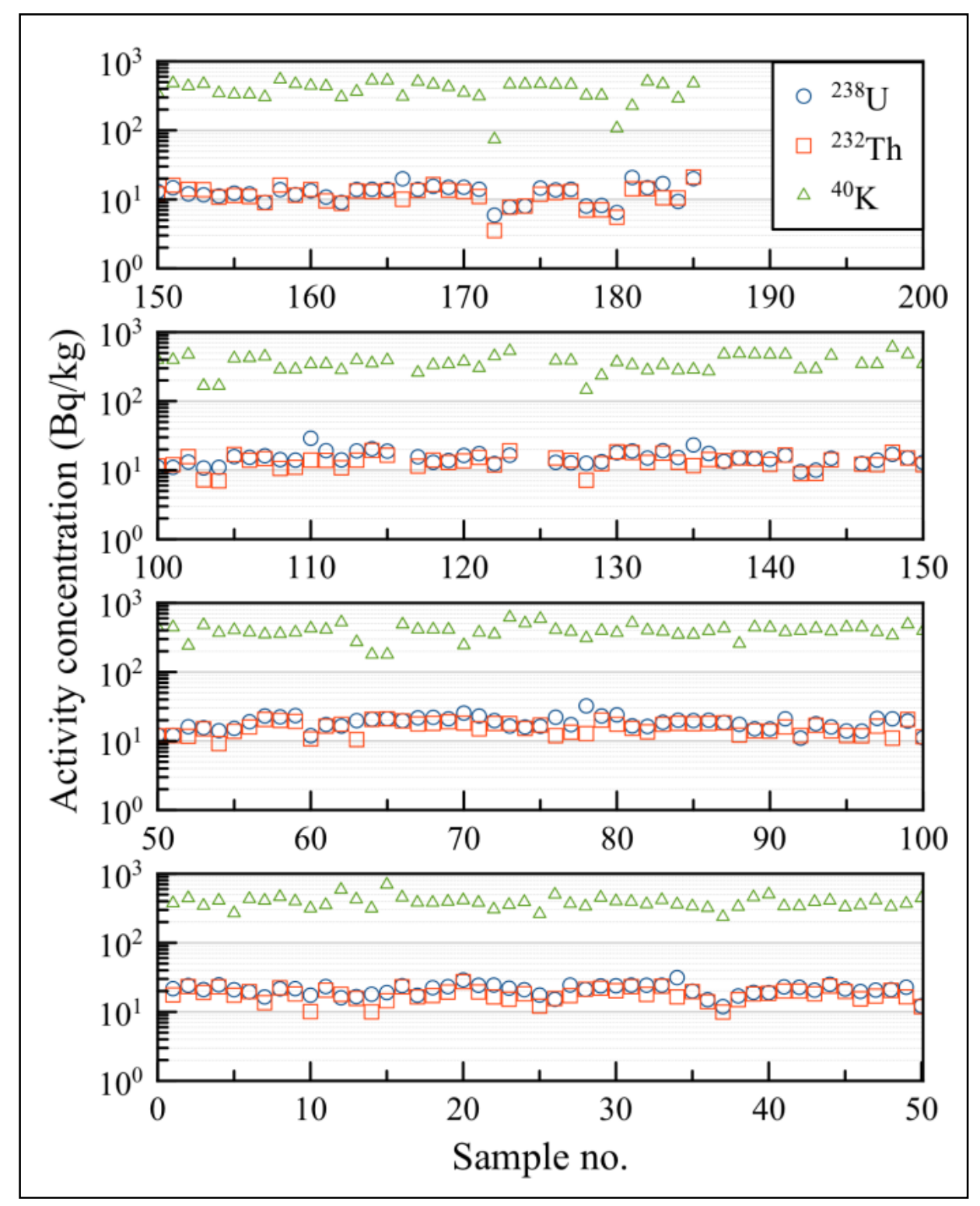

Fig.4. Weighted mean activity concentration distribution of ${ }^{238} \mathrm{U}$ and ${ }^{232} \mathrm{Th}$ decay chains, along with ${ }^{40} \mathrm{~K}$, for all samples across the state of Kuwait.

\subsection{Activity correlation: ${ }^{238} U /{ }^{232}$ Th and ${ }^{40} \mathrm{~K}$}

The measured activity concentration for all samples for ${ }^{238} \mathrm{U} /{ }^{232} \mathrm{Th}$ and ${ }^{40} \mathrm{~K}$ were correlated as shown in Fig. 5 as (a), (b) and (c), for ${ }^{238} \mathrm{U} /{ }^{232} \mathrm{Th},{ }^{40} \mathrm{~K} /{ }^{238} \mathrm{U}$, and ${ }^{40} \mathrm{~K} /{ }^{232} \mathrm{Th}$ respectively. There 
exists good correlation in (a) and (c), with positive correlation coefficients of 0.75 and 0.32 between the ${ }^{238} \mathrm{U} /{ }^{232} \mathrm{Th}$ and ${ }^{40} \mathrm{~K} /{ }^{232} \mathrm{Th}$. This may indicate common response to soil and sand chemical behaviour and other environmental processes as these nuclides are being distributed in the environment (Fujiyoshi and Sawamura, 2004, Khater et. al., 2001; El-Reefy et al., 2009). In 5 (b) however, only a weak correlation of 0.03 is obtained between the activity concentrations of ${ }^{40} \mathrm{~K}$ and ${ }^{238} \mathrm{U}$..

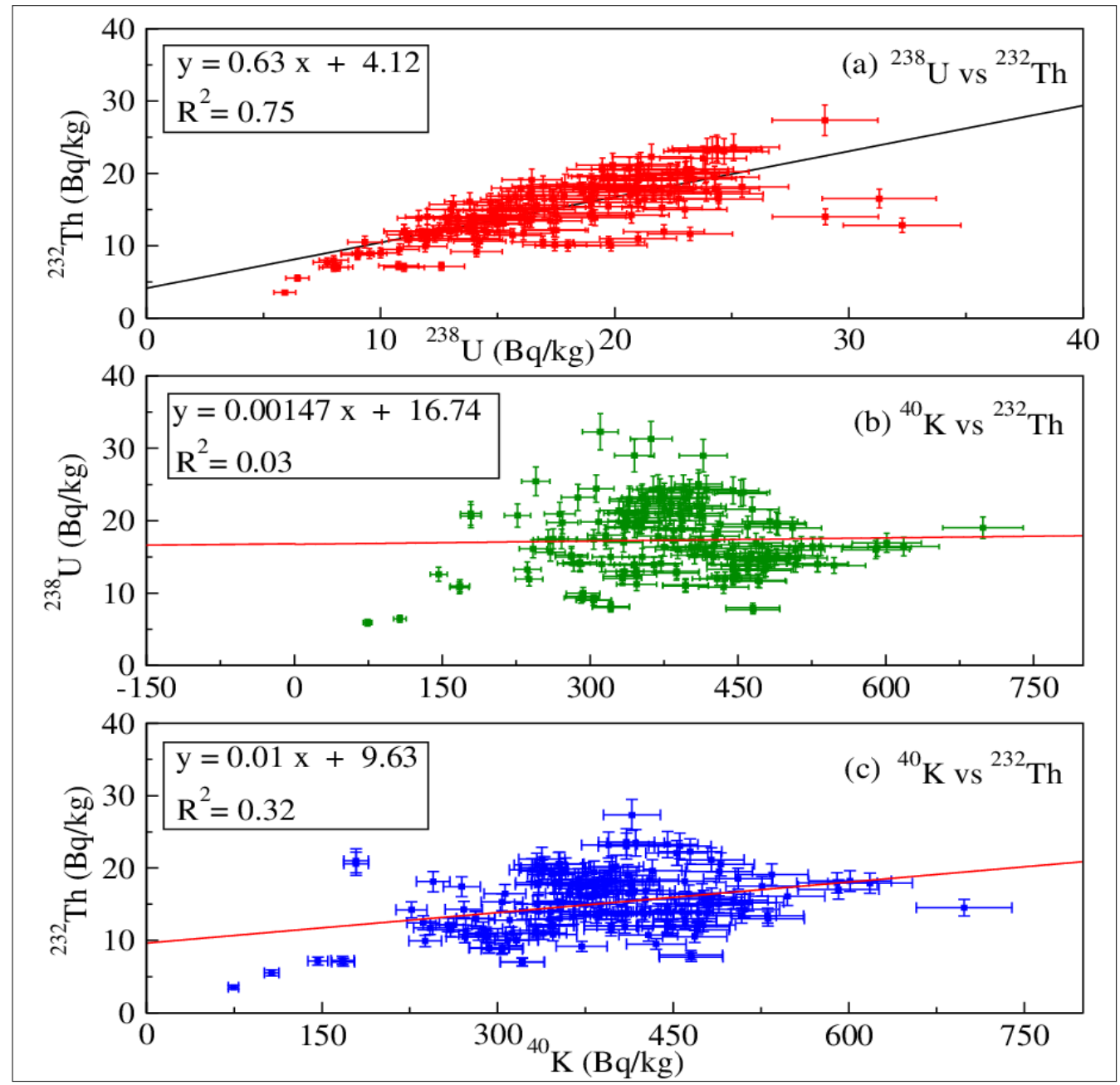

Fig.5. Activity correlation between (a) ${ }^{238} \mathrm{U} /{ }^{232} \mathrm{Th}$, (b) ${ }^{40} \mathrm{~K} /{ }^{238} \mathrm{U}$ and (c) ${ }^{40} \mathrm{~K} /{ }^{232} \mathrm{Th}$ for all measured samples across the whole of Kuwait. 
The geographical locations of the samples were then split into two sub groups, namely those from the North of the State of Kuwait (samples 1 - 65) and those from the central and southern regions of the country (samples $66-187$ as defined in Figure 1) Figure 6 shows the sub-grouped correlation of the ${ }^{238} \mathrm{U} /{ }^{232} \mathrm{Th}$ ratio for the samples from the Northern cohort (samples 1-65) of Kuwait and those for the rest of the country. Analysis of these data show different average ${ }^{238} \mathrm{U} /{ }^{232} \mathrm{Th}$ Activity concentration ratios of (a) 0.73 (a) and 0.51 (b) for the North and Central/Southern regions of Kuwait respectively. This average ratio is larger in the former case, indicating some additional ${ }^{238} \mathrm{U}$ over ${ }^{232} \mathrm{Th}$ in that region.

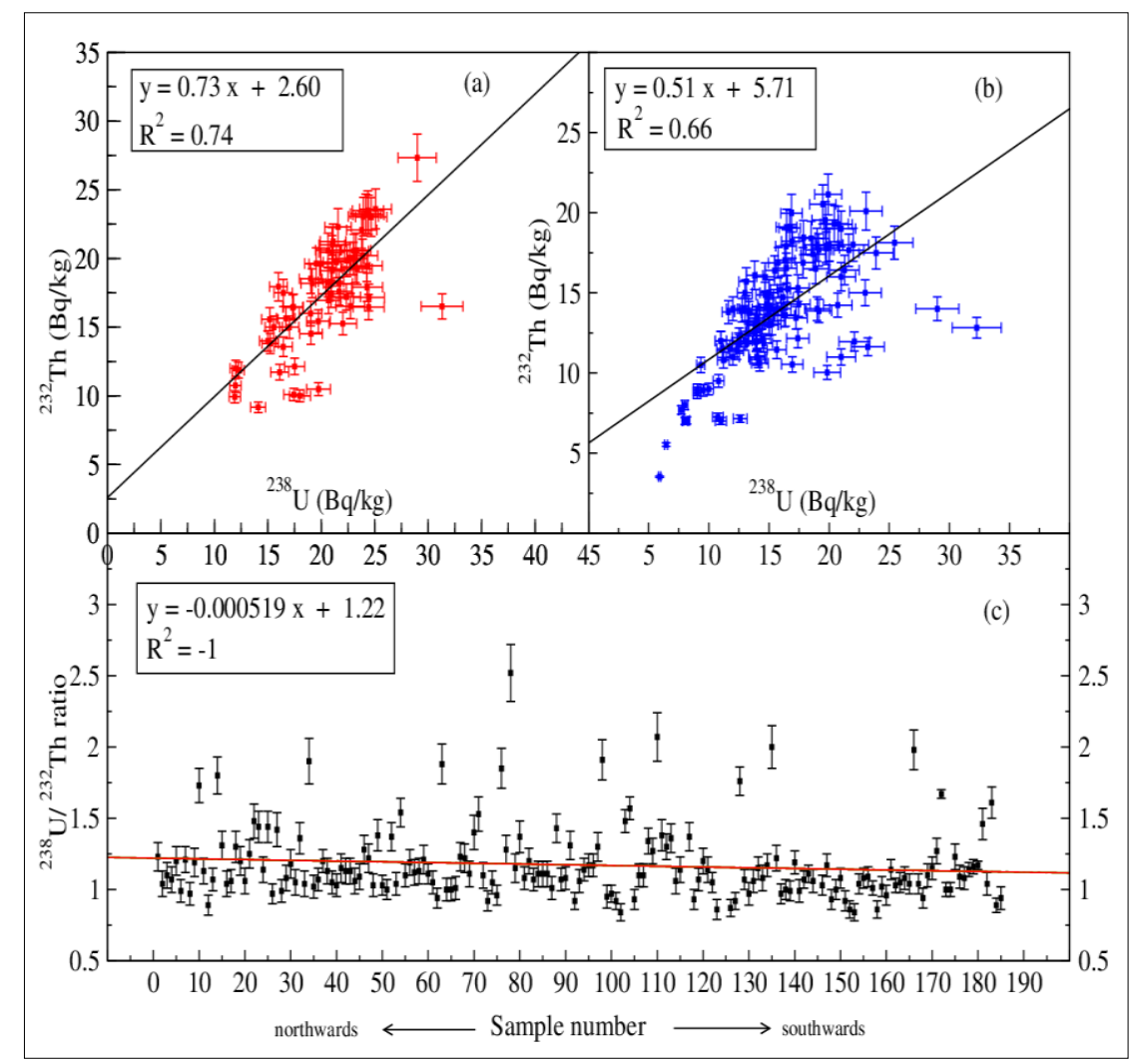

Fig.6. Measured activity ratio between ${ }^{238} \mathrm{U} /{ }^{232} \mathrm{Th}$ from the (a) north, (b) south, and (c) across the whole country for all measured samples.

\subsection{Radiation maps of Kuwait}

Results from the activity measurements were used to generate a radiological map of Kuwait from the 180 sample locations, as shown in Figures 7, 8 and 9 , for ${ }^{238} \mathrm{U},{ }^{232} \mathrm{Th}$, and ${ }^{40} \mathrm{~K}$ respectively. 


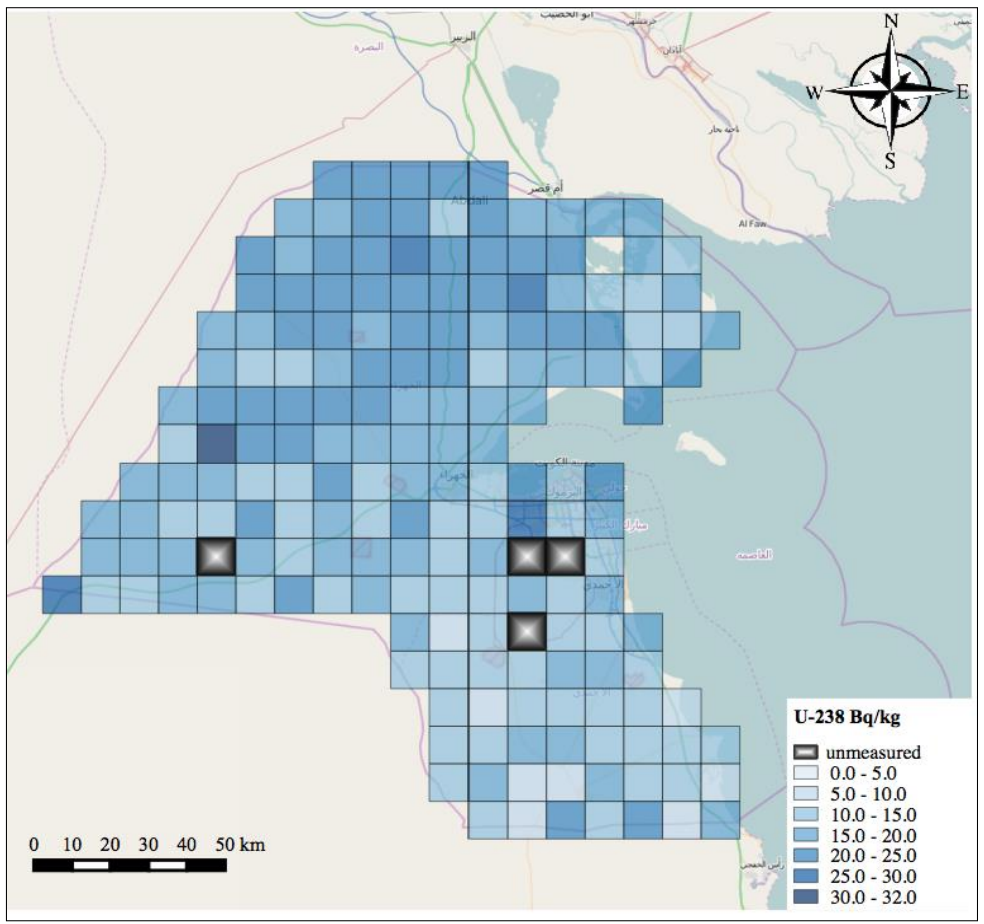

Fig.7. Radiation map of Kuwait showing the activity concentration distribution for ${ }^{238} \mathrm{U}\left({ }^{226} \mathrm{Ra}\right)$

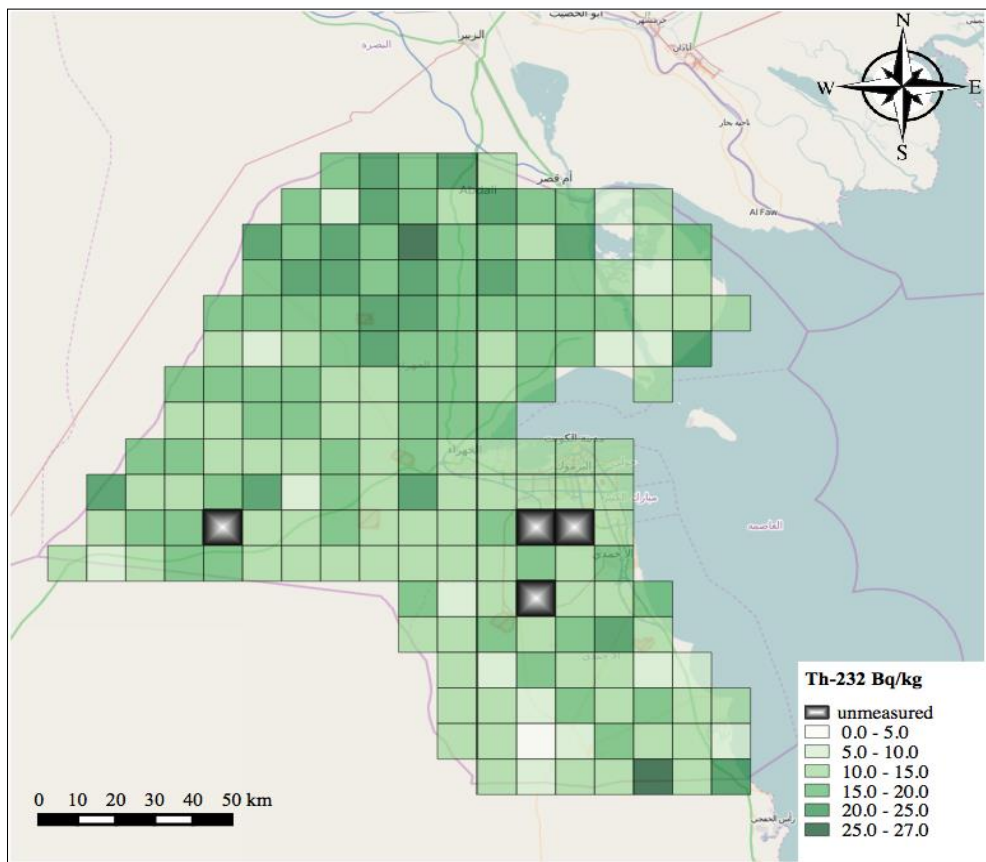

Fig.8. Radiation map of Kuwait showing the measured activity concentration distribution for ${ }^{232} \mathrm{Th}\left({ }^{228} \mathrm{Ac}\right)$. 


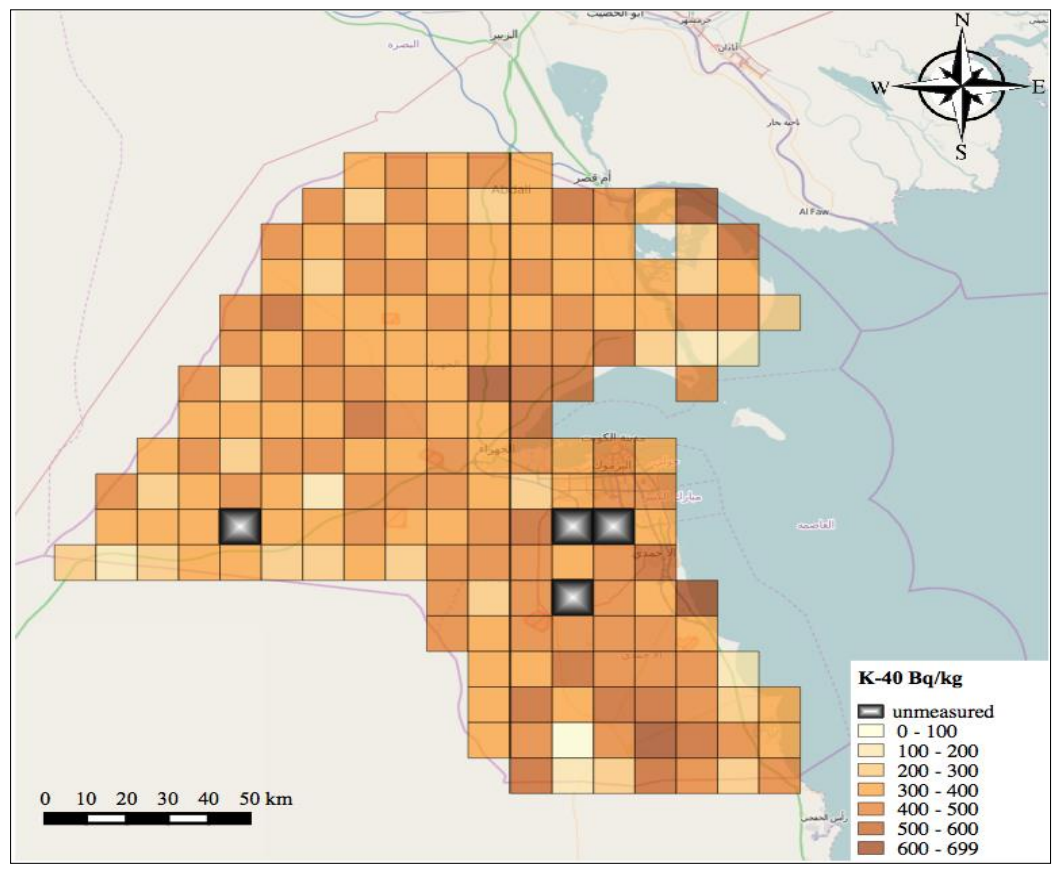

Fig.9. Radiation map of Kuwait showing activity concentration distribution for ${ }^{40} \mathrm{~K}$.

In general, the activity concentration is greater across the northern region compared to the central and southern part of Kuwait, with a systematically larger ${ }^{238} \mathrm{U} /{ }^{232} \mathrm{Th}$ ratio in the northern region (0.73) relative to the southern region (Fig 6, a and b). The northern part of the country suffered considerable bombardment by ground and air forces during the 1991 Gulf War (Barnaby, 1991) added to which are the location of many oils fields around the North of the countr which were affected by fire during the war (Saad and Azmi, 2002). The measured distribution of ${ }^{40} \mathrm{~K}$ is observed to remain rather constant across the entire region of Kuwait.

A summary is given in Table 1 of the mean activity concentrations for all the samples compared to other reported values from across the Middle East. The results of the present study give values below the world average for all the radionuclides. According to the year 2000 report of UNSCEAR (UNSCEAR, 2000), the worldwide activity concentrations of ${ }^{238} \mathrm{U},{ }^{232} \mathrm{Th}$ and ${ }^{40} \mathrm{~K}$ are in the range $17 \leftrightarrow 60,11 \leftrightarrow 64$, and $140 \leftrightarrow 850 \mathrm{~Bq} / \mathrm{kg}$ respectively, with mean respective concentrations of 35,30 and $400 \mathrm{~Bq} / \mathrm{kg}$. 
Table 1: A summary of mean evaluated activity concentration in all samples compared with some selected Middle Eastern states (UNSCEAR, 2000.)

\begin{tabular}{||l||c||c||c||}
\hline \multicolumn{4}{|c|}{ Mean activity concentration (Bq/kg) } \\
\hline \hline \multicolumn{1}{|c||}{ Country } & ${ }^{\mathbf{2 3 8}} \mathbf{U}$ & ${ }^{\mathbf{2 3 2}} \mathbf{T h}$ & ${ }^{\mathbf{4 0}} \mathbf{K}$ \\
\hline \hline Egypt (UNSCEAR, 2000) & 17 & 18 & 320 \\
Iran (UNSCEAR, 2000) & 28 & 22 & 640 \\
Iraq (Ahmed and Akrawy, 2015) & 14 & 7 & 452 \\
Jordan (Ahmed et al, 1997) & 25 & 15 & 188 \\
Oman (Goddard, 2002) & 30 & 15.9 & 225 \\
Saudi Arabia (Al-Trabulsy et al., 2011) & 11 & 23 & 641 \\
Syria (Al-Masri et al., 2006) & 15 & 24 & 116 \\
Yemen (Harb et al., 2012) & 48 & 42 & 939 \\
& & & \\
\hline \hline Worldwide (UNSCEAR, 2000) & $17-60$ & $11-64$ & $140-850$ \\
range & 35 & 30 & 400 \\
mean & 18 & 15 & 385 \\
\hline Current study
\end{tabular}

\subsection{Risk assessment}

The evaluated doses from this study are shown in Table 2 . The range of the radium equivalent concentration is from 17 . to $100 \mathrm{~Bq} / \mathrm{kg}$, with a mean of $69 \mathrm{~Bq} / \mathrm{kg}$, well below the published maximum permissible value of $370 \mathrm{~Bq} / \mathrm{kg}$ (UNSCEAR, 2000) which corresponds to an effective dose of $1 \mathrm{mSv}$ for the general public (Ajayi, 2009). The radium equivalent factor is generally used to assess the hazards associated with materials containing ${ }^{226} \mathrm{Ra},{ }^{232} \mathrm{Th}$, and ${ }^{40} \mathrm{~K}$ as seen from the equation (1), assuming $370 \mathrm{~Bq} / \mathrm{kg}$ of ${ }^{226} \mathrm{Ra}$ or $260 \mathrm{~Bq} / \mathrm{kg}$ of ${ }^{232} \mathrm{Th}$ or $4810 \mathrm{~Bq} / \mathrm{kg}$ of ${ }^{40} \mathrm{~K}$ produce the same gamma dose rate (UNSCEAR, 1982; Kumar et al. 2003). A summary is shown in graphical form in Fig. 10, with all present results lower than world mean values. 
Table 2. Results of radiological Risk factors measured for all samples from the current study

\begin{tabular}{|c|c|c|c|c|c|}
\hline \multicolumn{6}{|c|}{ "Radiological risk factors } \\
\hline & $\begin{array}{c}\mathrm{Ra}_{\mathrm{eq}} \\
(\mathrm{Bq} / \mathrm{kg})\end{array}$ & $\begin{array}{c}\text { Dose rate } \\
\mathrm{nG} / \mathrm{hr})\end{array}$ & $\begin{array}{l}\text { AEDE } \\
(\mu \mathrm{Sv} / \mathrm{yr})\end{array}$ & $\mathrm{H}_{\text {int }}$ & $\mathrm{H}_{\mathrm{ext}}$ \\
\hline $\begin{array}{l}\text { Arithmetic mean } \\
\text { Worldwide } \\
\text { mean value } \\
\text { range }\end{array}$ & $\begin{array}{c}370 \\
\text { NA* }^{*}\end{array}$ & $\begin{array}{c}57 \\
18-93\end{array}$ & $\begin{array}{c}70 \\
\text { NA* }^{*}\end{array}$ & $\begin{array}{l}\text { NA* } \\
\text { NA* }\end{array}$ & $\begin{array}{l}\mathrm{NA}^{*} \\
\mathrm{NA}^{*}\end{array}$ \\
\hline $\begin{array}{l}\text { Current study } \\
\text { Mean } \\
\text { minimum } \\
\text { maximum }\end{array}$ & $\begin{array}{c}68.5 \\
16.68 \\
100.21\end{array}$ & $\begin{array}{c}33.16 \\
7.96 \\
47.19\end{array}$ & $\begin{array}{c}40.7 \\
9.79 \\
58.04\end{array}$ & $\begin{array}{l}0.23 \\
0.06 \\
0.35 \\
\end{array}$ & $\begin{array}{l}0.19 \\
0.05 \\
0.27 \\
\end{array}$ \\
\hline
\end{tabular}

NA - not available

a (UNSCEAR, 2000)

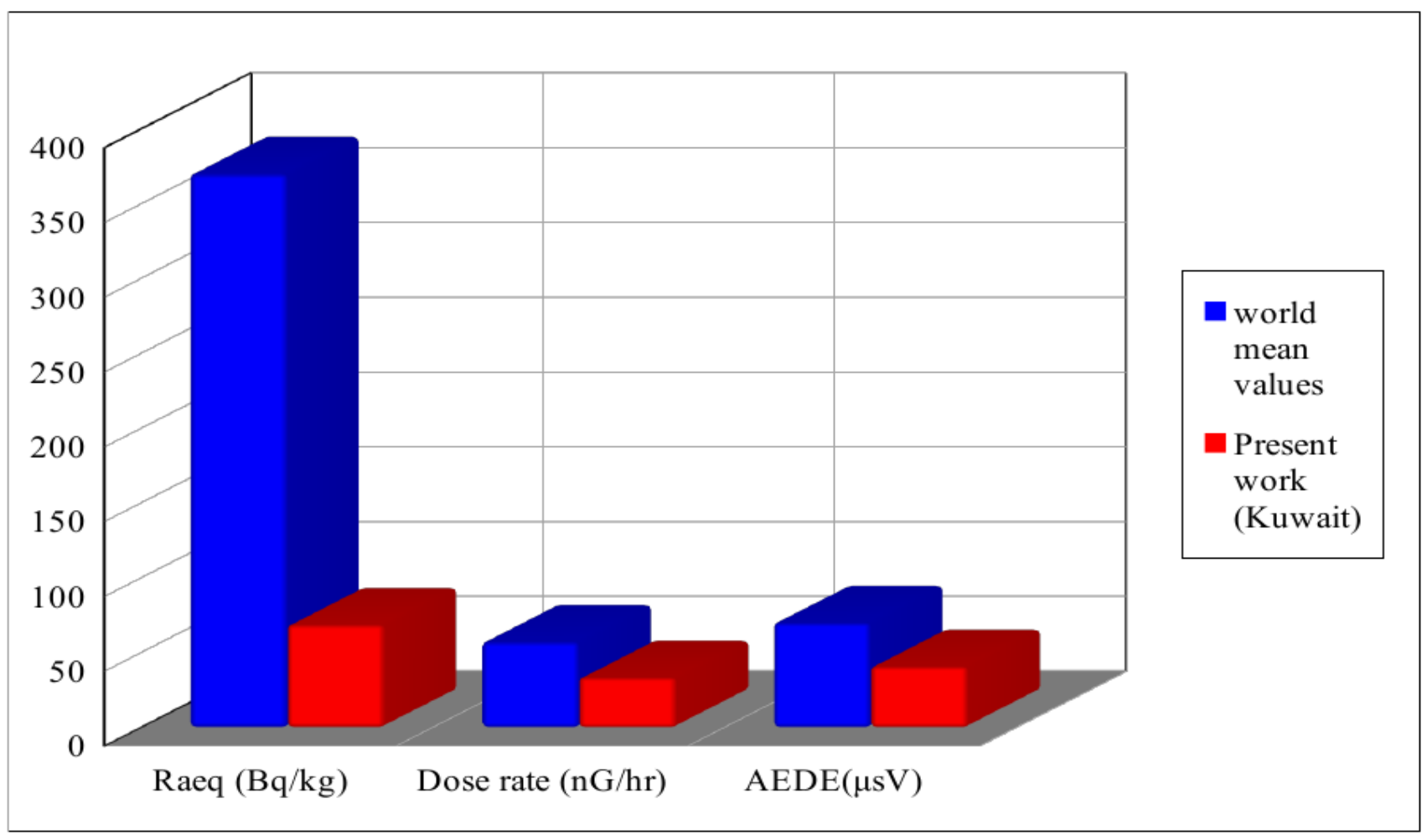

Fig.10. Results from this study compared with mean world mean values. 
Fig. 11 shows similar results across some Middle Eastern and North African countries, including Egypt, Jordan, Oman, Syria, Iran and Yemen, compared to the present study. The least values for radium equivalent are observed to be from Syria, Jordan, and Iraq, while the maximum value of $190 \mathrm{~Bq} / \mathrm{kg}$ is observed to be from the Yemen. The internal $\left(\mathrm{H}_{\mathrm{int}}\right)$ and external $\left(\mathrm{H}_{\mathrm{ext}}\right)$ hazards indices measure the extent of radiation exposure indoors due to radon gas and also externally. For all of these countries the values are less than 1 (Bou-rabee, 1997).

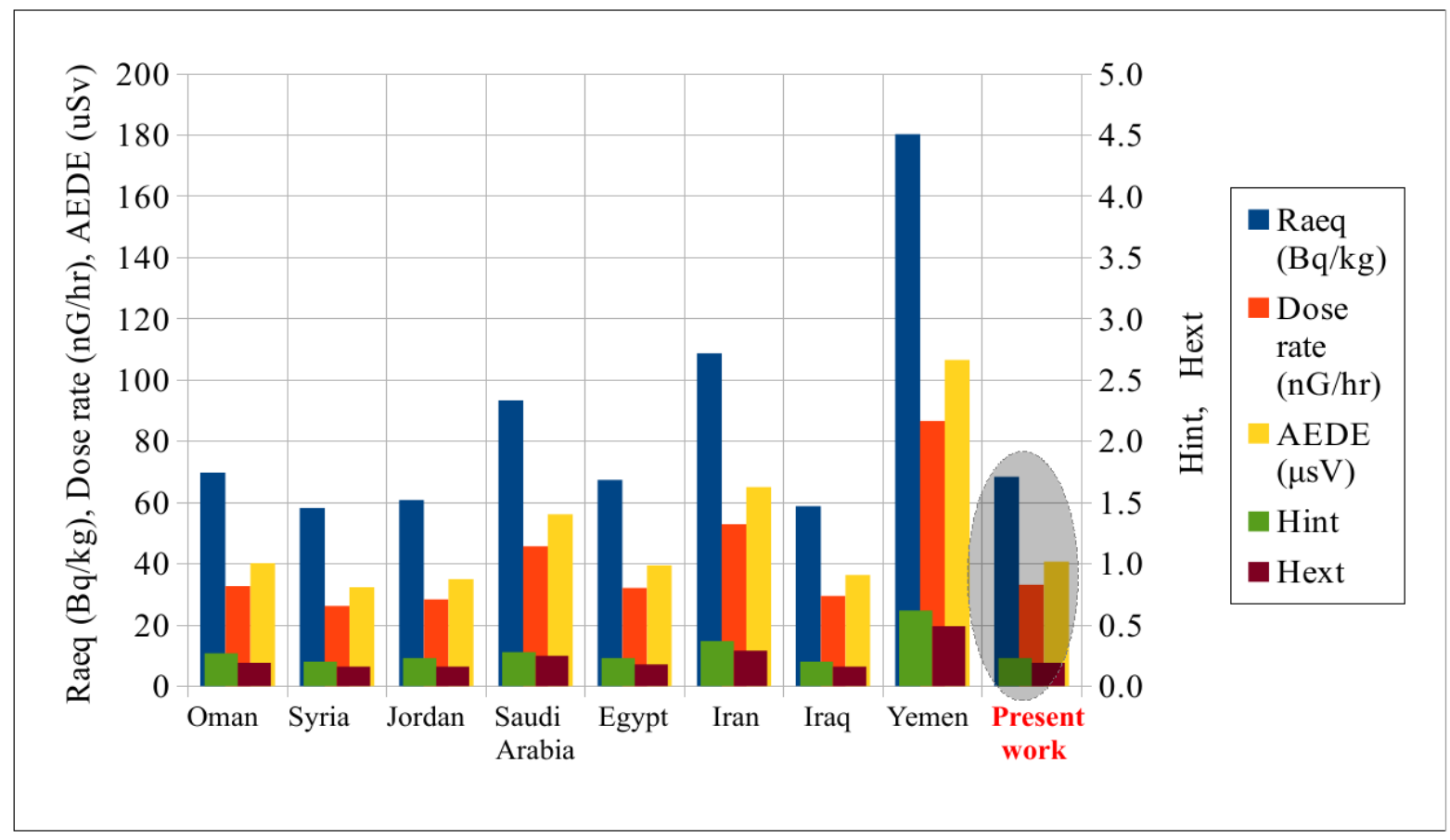

Fig. 11. Measured radiological factors from this study compared with those from the MiddleEastern region. The data is taken from the following references: Oman (Goddard, 2001) Syria (AlMasri et al, 2006) Jordan (Al-Hamarne and Awadallah, 2009) Saudi Arabia (El-Reefy et al., 2009) Egypt (UNSCEAR, 2000) Iran (UNSCEAR, 2000), Iraq (Ahmed, A. I. and Akrawy), Yemen (Harb et al., 2012)].

\section{Conclusions}

A total of 180 separate soil and sand samples from across the state of Kuwait were collected at 10 $\mathrm{km}$ intervals and in the current work have been measured with a view to determining their radioactivity concentration. These results have provided a baseline radiological map across the 
entire country of Kuwait. The measured activity concentrations ranges $6 \leftrightarrow 32 \mathrm{~Bq} / \mathrm{kg}$ and $4 \leftrightarrow 27$ $\mathrm{Bq} / \mathrm{kg}$ for ${ }^{238} \mathrm{U}\left({ }^{226} \mathrm{Ra}\right)$ and ${ }^{232} \mathrm{Th}\left({ }^{228} \mathrm{Ac}\right)$ respectively. The evaluated activity concentrations of ${ }^{238} \mathrm{U}$,

${ }^{232} \mathrm{Th}$ and ${ }^{40} \mathrm{~K}$ across all of the soil samples produce mean values of 18,15 , and $385 \mathrm{~Bq} / \mathrm{kg}$ respectively. A clear correlation is also observed between ${ }^{238} \mathrm{U}$ and ${ }^{232} \mathrm{Th}$ chain activity concentrations. The mean external dose-rate and radium equivalent values are $33.0 \pm 2.5 \mathrm{nG} / \mathrm{hr}$ and $68.5 \pm 5.0 \mathrm{~Bq} / \mathrm{kg}$ respectively. The internal and internal hazard indices are $0.23 \pm 0.02$ and $0.19 \pm 0.01$ respectively. The results of the activity concentrations of ${ }^{238} \mathrm{U},{ }^{232} \mathrm{Th}$, and ${ }^{40} \mathrm{~K}$ fall below the worldwide average values of 35, 40, and $400 \mathrm{~Bq} / \mathrm{kg}$ (UNSCEAR, 2000).

\section{Acknowledgements}

The authors would like to thank Messrs John-William Brown and Garry Strudwick of the Centre for Nuclear and Radiation Physics (CNRP) at the University of Surrey. A.D. Bajoga acknowledges support from Gombe State University and the Tertiary Education Trust Fund (TETFund) and N. Alazemi from the Kuwait Ministry of Health. P. H. Regan acknowledges support from the UK National Measurement Office (NPL) and STFC (UK).

\section{References}

Ahmed, A. I. and Akrawy, D. T, 2005. Measurement of Natural Radioactivity in Soil Samples from Bekhma, Kurdistan Region, Iraq. International Journal of Recent Research and Review Vol. VIII, Issue 4.

Ajayi, O. S.,2009. Measurement of activity concentrations of ${ }^{40} \mathrm{~K},{ }^{226} \mathrm{Ra}$ and ${ }^{232} \mathrm{Th}$ for assessment of radiation hazards from soils of the southwestern region of Nigeria. Radiation and Environmental Biophysics, 48(3), 323-332.

Al-Masri, M. S., et al., 2006. "External gamma-radiation dose to Syrian population based on the measurement of gamma-emitters in soils." J. Radioanaly. Nucl. Chem. 267.2 : 337-343.

Al-Hamarne, I.F., Awadallah, M.I., 2009. Soil radioactivity levels and radiation hazard assessment in the highlands of northern Jordan. Radiat. Meas. 44 (1), 102-110.

Al-Jundi, J., Al-Ahmad, N., Shehadeh, H., Afaneh, F., Maghrabi, M., Gerstmann, U. \& Oeh, U., 2008. Investigations on the activity concentrations of ${ }^{238} \mathrm{U},{ }^{226} \mathrm{Ra},{ }^{228} \mathrm{Ra},{ }^{210} \mathrm{~Pb}$ and ${ }^{40} \mathrm{~K}$ in Jordan phosphogypsum and fertilizers. Rad. Prot. Dos., 131(4), 449-454.

Barnaby, F., 1991. "The environmental impact of the Gulf War." Ecologist 21.4: 166-172.

Baeza, A., Corbacho, J. A., Guillén, J., Salas, A., \& Mora, J. C.,2011. Analysis of the

differentsource terms of natural radionuclides in a river affected by NORM (Naturally Occurring 
Radioactive Materials) activities. Chemosphere, 83(7), 933-940.

Berekta, J. and Mathew, P.J., 1985. Natural radioactivity of Australian building materials, 139 Industrial wastes and by-products. Health Phys. 48: p. 87-95.

Bou-Rabee, Firyal., 1997. "Soil radioactivity atlas of Kuwait." Environment international 23.1: 515.

Browne, E., Firestone, R. B., \& Shirley, V. S.,1986. Table of radioactive isotopes. In: Willey-Interscience, New York.

Dawood, Hasan Issa, 2011 "Measurement of Radioactivity for Radium 226 Isotopes in some Soil Samples from Different Regions in Karbala Governorate using Gamma Ray Spectrometry." Journal of Babylon University, Pure and Applied Science 2: 19.

Dovlete, C., Povinec, P.P., 2004. Quantification of Uncertainty in Gamma-Spectrometric Analysis of Environmental Samples, IAEA-TECDOC-1401, International Atomic Energy Agency, Austria, 103-126.

Dragović S., Janković Lj, Onjia A. 2006. Assessment of gamma dose rate from terrestrial exposure in Serbia and Montenegro, Radiation Protection and Dosimetry, 121 (3) 297-302.

El-Reefy, H.I., et al., 2009. Distribution of gamma-ray emitting radionuclides in the environment of Burullus Lake:I. Journal of Environmental Radioactivity 87, 148-169.

Fujiyoshi, R., \& Sawamura, S.,2004. Mesoscale variability of vertical profiles of environmental radionuclides $\left(40 \mathrm{~K}, 226 \mathrm{Ra}, 210 \mathrm{~Pb}\right.$ and ${ }^{137} \mathrm{Cs}$ ) in temperate forest soils in Germany. Science of the Total Environment, 320(2), 177-188.

Gilmore, G.R., 2008. Practical Gamma-ray Spectrometry, $2^{\text {nd }}$ edition, John Wiley \& Sons Ltd., Chichester.

Goddard, C. C.,2002. Measurement of outdoor terrestrial gamma radiation in the Sultanate of Oman. Health Physics, 82(6), 869-874.

Harb, S., El-Kamel, A. E. H., Abbady, A. E. B., Saleh, I. I., \& El-Mageed, A. I. A.,2012. Specific activities of natural rocks and soils at quaternary intraplate volcanism north of Sana'a, Yemen. Journal of Medical Physics/Association of Medical Physicists of India, 37(1), 54.

IAEA, 2003. Extent of Environmental Contamination by Naturally Occurring Radioactive Material (NORM) and Technological Options for Mitigation, Technical Reports Series No.419, International Atomic Energy Agency, Vienna.

Jallad, K.N.,2013. Radioactive investigation of sand from the northern region of Kuwait. Environ. Nat. Resour. Res. 3 (4).

Khatera, Ashraf E.M., Higgya R. H., Pimpl M.,2001. Radiological impacts of natural radioactivities in Abu-Tartor phosphate deposits, Journal of Environmental Radioactivity (55), 
$255-267$.

Kumar, A., Kumar, M., Singh, B., \& Singh, S., 2003. Natural activities of 238U, 232Th and 40K in some Indian building materials. Radiation Measurements, 36(1), 465-469.

Newman, R. T., Lindsay, R., Maphoto, K. P., Mlwilo, N. A., Mohanty, A. K., Roux, D. G., ... \& Hlatshwayo, I. N., 2008. Determination of soil, sand and ore primordial radionuclide concentrations by full-spectrum analyses of high-purity germanium detector spectra. Applied Radiation and Isotopes, 66(6), 855-859.

Saad, H.R., Al-Azmi, D., 2002. Radioactivity concentrations in sediments and their correlation to the coastal structure in Kuwait. Applied Radiation and Isotopes 56 (6), 991-997.

Santawamaitre, T., Malain, D., Al-Sulaiti, H. A., Bradley, D. A., Matthews, M. C., \& Regan, P. H., 2014. Determination of $238 \mathrm{U}, 232 \mathrm{Th}$ and $40 \mathrm{~K}$ activity concentrations in riverbank soil along the Chao Phraya river basin in Thailand. Journal of Environmenta Radioactivity, 138, 80 86.

UNSCEAR, 1998. Report Vol.1., General Assembly, United Nations, New York.

UNSCEAR, 2000. Sources and Effects of Ionizing Radiation, United Nations Scientific

Committee on the Effect of Atomic Radiation Report Vol.1 to the General Assembly, with Scientific Annexes. United Nations Sales Publication, United Nations, New York.

Xhixha, G., Baldoncini, M., Callegari, I., Colonna, T., Hasani, F., Mantovani, F. \& Kaçeli, M. X., 2015. A century of oil and gas exploration in Albania: Assessment of Naturally Occurring Radioactive Materials (NORMs). Chemosphere, 139, 30-39. 